\title{
Gerak Muslimah di Antara Maraknya Feminisme dan Isu Radikalisme: Analisis Pedagogi
}

\author{
Aminah \\ Institut Parahikma Indonesia, Gowa, Sulawesi Selatan
}

\begin{abstract}
There are various styles of feminism that have been developing today. Generally, there are terms called classic feminism and contemporary feminism. Classical feminism consists of liberal, Marxist, Radical, and Socialist feminism and they tend to be atheistic. Whereas contemporary feminism that is increasingly developing in almost all parts of the world is the third world feminism, multicultural feminism, religion feminism, and ecofeminism. This contemporary feminism includes atheists and theists. This discussion of feminism are explored in this article by interpreting freedom and equality between the Indonesian and Islamic contexts.

On the other hand, the issue of radicalism is an issue that is widely discussed with the existence of several events that lead to terrorism and the desire to establish a system of caliphate on the earth of the motherland. Deradicalization of radicalism is characterized by selfishness, symbolism, and closed textual corpus. They should be transformed into a more moderate understanding.Therefore, as Indonesian moslem women, these two things need to be explored further because they affect women as the first madrasa and the nation pillars. Moslem women must be equipped with several important components in positioning themselves as $a^{\prime}$ whole person' in this millennial century. Those components are knowing the purpose of creation, building world views, recognizing self-potential, and becoming productive individuals in the domestic and social spheres.The creation of an Indonesian Moslem woman with a firm, virtuous, productive and knowledgeable principle is a nation milestone as a daughter, mother, wife and public sector. The women who become ' a whole person' will be able to contribute in overcoming religious and national polemics.
\end{abstract}

Keywords: Indonesian moslem women movement, feminism, radicalism, pedagogy

\section{Pendahuluan}

Sejak emansipasi wanita yang muncul di Indonesia, R.A. Kartini menjadi sosok tauladan perempuan untuk kesetaraan gender perempuan dan laki-laki. Pedagogi atau pendidikan menjadi salah satu aspek penting dalam kehidupan yang memeiliki sumbangsih besar dalam membentuk peradaban bangsa. Terbentuknya kurikulum menjadi acuan bagi berjalannya roda pendidikan di Indonesia.

Namun bagaimana halnya deengan feminism? Perlukah feminism menjaadi salah satu materi pembelajaran atau penunjang di dunia pendidikan formal? Hal ini masih jadi perdebatan. 


\section{An-Nisa', Volume XI Nomor 2 Desember 2018}

Mengingat focus pada gender dan feminism menjadi pembahasan pilihan di jenjang perkuliahan. Sementara di tingkat dasar hingga sekolah menengah atas, gagasan kesetaraan gender hanya diajarkan sekilas dalam ilmu agama, ilmu sosial, dan pemdidikan kewarganegaraan.

Melihat pelbagai persoalan yang muncul dikarenakan diskriminasi budaya maupun agama, membuat isu feminisme perlu dijadikan salah satu pembelajaran penting dalam mejawab fenomena kekinian. Perempuan zaman now diperhadapkan dengan tantangan zaman yang cukup pelik. Ada beberapa isu feinisme yang sebenarnya melanggar kodrat kemanusiaan dan koridor

yang semestinya, tetapi di sisi lain stigma subordinasi, domestifikasi, dan stereotip tentang perempuan terus menggema hingga saat ini.

Jadi perlu adanya pemetaan, dari perkembangan feminism klasik hingga kontemporer, ada beberapa hal yang bisa di petik da nada juga yang perlu difilter karena tidak sejalan dengan fitrawi manusia, aturan kemanusiaan, serta keadilan. Aspek yang perlu diperhatikan dalam membangun jati diri perempuan terutama menjadi muslimah sejati adalah mengetahui tujuan penciptaan, membangun pandangan dunia, mengenali potensi diri, dan menjadi pribadi produktif dalam lingkup domestik maupun rana sosial.

Mayoritas jumlah ummat islam di Indonesia seharusnya menjadikan gerak muslimah sebagai garda depan pengusung peradaban di negara ini. Terciptanya pribadi yang berprinsip teguh, berbudi luhur, produktif, dan berilmu adalah bekal utama sebagai seorang anak, ibu, istri,dan bagian dari penggerak masyarakat di sektor publik.

\section{Pendidikan Dan Feminisme Indonesia}

Hari kemerdekaan Indonesia, pada tanggal 17 Agustus seringkali dijadikan wadah untuk berkreasi. Perlombaan serta lomba menjadi ajang unjuk bakat. Begitupula dengan hari Kartini yang seolah menjadi hari dimana seorang sosok perempuan bernama R.A. KArtini menjadi pelopor bangsa dan tauladan perempuan Indonesia. Di satu sisi, nilai sebuah pendidikan di dua agenda ini menjadi acuan miniatur kebangsaan. Anak-anak terlihat gembira dengan mengenakan pakaian yang menunjukkan cita-citanya. Di sisi lain kegiatan karnaval menunjukkan bahwa ekerjaan adalah karir tertentu seperti dokter, guru, polisi, dll. 
Lantas bagaimana denga pekerjaan seperti tukang jahit, ibu rumah tangga, wiraswasta, dan menjadi seorang ibu yang berhasil mendidik anaknya menjadi orang yang berhasil? Mindset seperti ini seolah menjadi tolok ukur masyarakat bahwasanya pekerjaan yang diakui di tengah masyarakat adalah pada profesi tertentu saja. Secara sadar maupun tak sadar, lembaga pendidikan sedang memperlihatkan bahwasanya pekerjaan tertentu yang tidak ada di karnaval sebagai profesi yang tidak mencerminkan oang yang berpendidikan.

Padahal, untuk mecetak generasi bangsa yang cerdas, dibutuhkan sosok perempuan tangguh yang mampu menjadi tauladan bagi anaknya, tidak hanya pendidikan dari sekolah. Lingkungan juga terkadang mengajarkan bahwasanya pekerjaan yang belum tentu menghasilkan uang banyak tapi juga mulia itu banyak macamnya, misalnya pemulung, penjual di pasar loak, pembantu, dan sebagainya. Sebaiknya pendidikan juga memperlihatkan bahwasanya seluruh pekerjaan itu mulia meskipun tak berpenghasilan banyak, yang penting berkah.

Pendidikan di Indonesia khususnya bagi kaum hawa, mejadikan kartini sebagai sosok yang mengubah nasib perempuan di kala itu. Doktrinasi budaya jawa serta doktrin patriarki menjadikan Kartini sebagai salah satu pemberontak di sejarahnya dalam melawan keterkungkungan budaya. Pemikirannya utuk keluar dari hegomoni public pada umumya, menginspirasi perempuan untuk mengenyam pendidikan lebih tinggi.

Semangat Kartini dalam menguak makna pendidikan dari ikatan budaya, mengingatkan bahwa perempuan juga adalah manusia yang memiliki kodrat yang sama dengan lelaki dalam hak untuk diperlakukan sama, hak untuk belajar, hak untuk bebas, dan berbagai hak azasi manusia lainnya. Kebersamaan hak atau equality menjadikan pendidikan sebagai gerbang yang menempa perempuan untuk menjadi pribadi yang lebih bermanfaat dan mulia di masyarakat serta lingkup domestiknya.

Tipologi pendidikan yang ada di Indonesia tidak terlepas dari kurikulum dan ideologi bangsa. Salah satu cara untuk membebaskan pikiran yang terbelenggu pada ketertindasan adalah melalui pendidikan. Kurikulum pendidikan dicetuskan untuk membentuk pemikiran-pemikiran d. Kurikulum merupakan acuan pelaksanaan pendidikan. 


\section{An-Nisa', Volume XI Nomor 2 Desember 2018}

Pada beberapa hal, kurikulum diubah hanya sebatas ada perubahan materi atau bahan. Namun sebenarnya, secara hakekat pendidikan, perubahan itu juga harus terkait pada tingkah laku dan berpikir guru. Fulan dan Park dalam Seller dan Miller merumuskan bahwa makna dari sebuah perubahan yang harus dipahami adalah komponen yang terlibat dalam pendidikan agar perubahan yang dilakukan dapat diimplementasikan dengan baik. ${ }^{1}$

Tingkah laku yang berkaitan dengan etika adalah ciri budaya bangsa nan luhur. Selain itu, agam apun sangat menjunjung tinggi nilai penghormatan pada sesama, menghargai perbedaan dan kekurangan orang lain, sikap saling tolong menolong dan lain sebagainya adalah implementasi dari sebuah mahakarya pendidikan. Tentunya figur seorang guru dala memberikan contoh bagi siswanya sangat berperan penting dalam membentuk karakter anak bangsa.

Di samping itu, kurikulum pendidikan yang ada di Indonesia diharapkan memperlihatkan kesetaraan gender yang keluar dari segmen penidasan dan ketidakadilan. Sejak awal munculnya islam, perempuan telah diangkat derajatnya setara dengan kaum lelaki. Sementara di Indonesia, fenomena feminisme dinilai muncul di masa Kartini. Adanya beberapa korespondensi yang dilakukan Kartini dengan sahabat-sahabatnya yang dari Belanda membuka cakrawala berpikir kritisnya untuk mengubah diri agar lebih maju. Kemauan pola pikir adalah salah satu komponen terjadinya perubahan pada kurikulum pendidikan.

Adanya beberapa kali perubahan kurikulum berpatokan pada apa yang disaran kan oleh Bee dalam Hamalik yakni ada tiga hal yang mempengaruhi perubahan kurikulum antara lain: (1) the essential curriculum yang meliputi pengetahuan dan keterampilan minimum yang pencapaiannya di ukur denga tehnik "quality control", (2) the potential curriculum yang meliputi pengetahuan dan keterampilan yang dituntut untuk meliputi setiap anak, selaras dengan perkembangan anak, jenjang sekolah, serta kebutuhan masyarakat yang bersangkutan, dan untuk ini diperlukan evaluasi yang kontinyu, (3) the vocational curriculum yang meliputi keterampilan

\footnotetext{
${ }^{1}$ J.P. Miller \& W. Seller. Curriculum, Perspectives, and Practices. (New York aand London: Longman, 1985), h. 13
} 
dan pengetahuan yang khas yan harus dimiliki sejumlah maka sehubungan dengan kebutuhan tenaga kerja pada masyarakat. ${ }^{2}$ Beberapa dari contoh kurikulum ini pro gender, adapula yang kurang responsif gender.

Peringatan hari Kartini yang biasanya menunjukkan kesetaraan profesi dengan lelaki tidak serta merta menjamin bahwa nantinya ketika dewasa para lelaki bisa terus menghormati derajat perempuan yang ada di sekitarnya. Budaya patriarki yang berkembang di masyarakat serta komoditi kapitalisme masih menjerat perempuan. Peringatan hari Kartini seharusnya bukan hanya memperhatikan dari segmen pakaian, tapi juga membentuk mindset peserta didik agar kelak menjadi manusia yang tidak mendiskriminasi orang lain.

Mindset atau pola pikir yang membentuk stigma berpikir logis serta bijak diharapkan mampu menjawab kasus pelecehan seksual yang terjadi masyarakat, subordinat pada tempat kerja, stereotip pada perempuan, masih kerap kali ditemukan di tengah kasus yang menimpa perempuan di masyarakatnya. Hal ini menjadi tugas pendidik yang tidak hanya di ruang akademisi, tapi juga keluarga, teman, serta lingkungan.

Salah satu contoh kurikulum yang menginginkan generasi bangsa akan datang agar memiliki mental serta karakter yang sesuai dengan ideology bangsa, Pancasila, adalah Kurikulum 2013. Pancasila diharapkan tidak menjadi sekedar butiran tanpa makna. Melainkan menjadi spirirt gerak bagi seluruh rakyat Indonesia agar mampu menjalani segala segmen kehidupan dengan semangat kebhinekaan, kemanusiaan, persatuan, etika, demokrasi, serta keadilan. Lalu, bagaimana dengan pendidikan mengenai wacana feminism?

Dengan melihat kemungkinan yang ada, ketika feminism diajarkan, hal ini diharapkan memberi kesadaran pada seluruh siswa baik lelaki maupun perempuan agar nantinya tidak saling menjatuhkan. Selama ini, stigma diskriminasi yang seringkali dilakukan adalah yang menyalahkan kaum lelaki yang menindas kaum perempuan. Teori inilah yang seringkali digaungkan oleh aliran feminisme. Lelaki diajak agar turut mengambil peran dalam memahami segala aspek yang menjauhkan diri dari tindakan dikotomis dan marginalisasi satu sama lain.

\footnotetext{
${ }^{2}$ Oemar Hamalik, Dasar-Dasar Pengembangan Kurikulum. (Bandung: PT. Remaja Rosdakarya, 2006), h.108
} 


\section{An-Nisa', Volume XI Nomor 2 Desember 2018}

Lembaga pendidikan formal merupakan lembaga pendidikan yang mempunyai beberapa tanggung jawab tidak hanya sebatas pada fungsi edukasi melainkan juga tanggung jawab moril guna mengajar serta mendidik tunas bangsa. Feminisme diharapkan mampu menjelaskan nilainilai sederhana yang seringkali terabaikan khususnya dalam kehidupan sehari-hari. Cara memperlakukan sesama manusia tanpa menjadikan lelaki sebagai musuh dan perempuan sebagai korban.

Tanpa kesadaran yang mendalam dan pemahaman yang baik, intensitas interaksi akan menimbulkan sikap yang berpotensi menimbulkan diskriminasi antara perempuan dan laki-laki. Bentuk pendidikan feminismeyang ditawarkan pun bisa bervariasi tergantung objek dan tujuannya. Bisa saja feminisme diterapkan sebagai salah satu mata pelajaran wajib atau hanya menjadi waca penunjang di institusi pendidikan.

Di beberapa mata pelajaran di institut formal pendidikan, pelajaran agama, pendidikan kewarganegaraan ataupun ilmu-ilmu sosial telah menyelipkan penjelasan mengenai kesetaran gender. Namun, sepertinya hal ini belum menunjukkan usaha yang maksimal untuk memberikan edukasi mendalam tentang feminisme. Hidayat berpendapat bahwa kurikulum yang terdapat dalam pendidikan memiliki relasi yang timpang dan dominasi laki-laki dalam kegiatan pelaksanaannya. Feminis beranggapan bahwa kurikulum merupakan sarana ampuh untuk melanggengkan relasi timpang antara laki-laki dan perempuan. Hal ini disebabkan oleh sistem pendidikan paling berkuasa dalam mencampuri reproduksi hubungan soasial. ${ }^{3}$

Masih adanya kasus kekerasan dalam rumah tangga (KDRT), diskriminasi dalam urusan profesi, pelecehan seksual,atau kadar pengakuan terhadap keunggulan yang dimiliki oleh perempuan, menjadikan gerakan feminisme terus memperjuangkan kesetaraan ini dan pengakuan bahwa di beberapa sisi kualitas dan kapabilitas perempuan bisa sejajar dengan lakilaki.

Ketua Komite FemFest 2017 Anindya Restuviani mengatakan bahwa feminisme bisa membantu kita sebagai masyarakat Indonesia untuk memenuhi hak keadilan gender dan membebaskan semua orang untuk dapat memilh apa yang terbaik bagi mereka. Sayangnya,

\footnotetext{
${ }^{3}$ Rahmat Hidayat. Pengantar Sosiologi Kurikulum, (Jakarta: RajawaliP ress, 2011), p. 124-125
} 
menurut Anindya, belum banyak yang memahami feminisme karena lemahnya pendidikan mengenai feminisme di Indonesia. "Indikator kesetaraan gender bukan hanyalah berapa banyak anak perempuan yang sekolah, atau berapa banyak wanita karir yang ada di Indonesia, namun lebih kepada pilihan dan kesempatan yang diberikan kepada kita semua," tambahnya.

Bias gender yang dipaparkan oleh Mansour Fakih ${ }^{4}$ yang mengakibatkan Ketidakadilan gender (gender inequalities) adalah adanya marginalisasi, subordinasi, pandangan stereotip, kekerasan (dalam rumah tangga) maupun pelecehan seksual, serta beban ganda. Hal ini ironisnyadiperkenalkan secara sadar maupun tak sadar pada beberapa buku pelajaran melalui pelbagai pendekatan semiotika. Semiotika ini juga dikenal sebagai sebuah disiplin yang mempelajari segala sesuatu yang dapat digunakan untuk berdusta ${ }^{5}$. Zulmi dan Lisytani ${ }^{6}$ menjabarkan ada empat bentuk bias gender yang nampak pada buku sekolah, antara lain:

a. Bias gender dalam peran kerja: disosialisasikan melalui bias peran publik dan domestik. Dominasi laki-laki pada peran publik seperti kerja kantoran, kerja di kebun ataupun sawah, sebagai pencari nafkah. Sementara peran domestik seperti belanja ke pasar, memasak, membersihkan rumah, mengurus anak, melayani suami sebagai peran ibu rumah tangga. Peran lelaki dalam peran domestik hanya bersifat membantu saja seperti menyiram bunga atau membersihkan tempat tidur. Perempuan di rana publik lebih ditampilkan sedang bawa tas kerja saja.

b. Bias gender dalam nilai dan sifat: Hal ini diperlihatkan pada sifat maskulin dan feminin serta cara berpakaian. Maskulinitas tercermin pada lelaki sebagai sosok yang enterprising (giat berusaha, disiplin, rasionla, aktif, berwawasan luas, ingin dilayani, mandiri, serta percayadiri. Sedangkan feminitas cenderung pasif, peduli, patuh, sopan, siap melayani, menghargai, emosional, cengeng, dan penuh kasih sayang.

\footnotetext{
${ }^{4}$ Mansour Fakih, Analisis Gender dan Transformasi Sosial. (Yogyakarta: Pustaka Pelajar. 2013).

${ }^{5}$ Yasraf Amir Piliang. Hipersemiotika: Tafsir Cultural Studies Atas Matinya Makna. (Bandung: Jalasutra, 2003), h. 44

${ }^{6}$ Billah Nurlaili Zulmi dan Refti Handini Lisytani, Bias Gender dalam Buku Tematik Siswa Kurikulum 2013: (Studi Semiotika Ketidaksetaraan Gender dalam Pendidikan) . (Jurnal Paradigma Vol. 05 No.3 Tahun 2017). h. 7
} 


\section{An-Nisa', Volume XI Nomor 2 Desember 2018}

Dari segi gaya berpakaian, laki-laki banyak ditampilkan dengan kemeja, kaos, celana pendek. Perempuan ditampilkan dengan gaya berpakain menggunakan rok, kerudung, aksesoris bando atau pita, dan celana.

c. Bias gender dalam status sosial: disosialisasikan melalui peebedaan kepemimpinan dan pendidikan. Kepemimpinan meempatkan lelaki pada jiwa leadership sehingga statusnya lebuh unggul dibanding perempuan. Lelaki menjadi kepala sekolah, memimpin upacara, dan berani tampil di depan. Tidak demikian dengan perempuan yang seakan sama sekali tidak memiliki jiwa kepemimpinan. Bias gender juga menampilkan perbedaan bacaan, dimana lelaki suka koran dan perempuan suka majalah.

d. Bias gender dalam kegemaran: disosialisasikan melalui perbedaan olahraga atau hobi. Hobi lelaki yang suka dengan bola, mobil-mobilan basket, sementara perempuan suka menari. Selain itu, permainan lelaki berhubungan dengan mengasah otak dan penuh tantangan keberanian, seperti bermain bola,perang, bala mobil, dll. Sementara perempuan tidak jauh dari urusan domestic seperti menghias rumah, kolase, menyiram bunga, dan merawat bayi. Kepemilikan barang pun menempatkan lelaki denga atribut mobil-monilan, kelereng, kartu, tembak, dll. Sedangkan perempuan memiliki mainan boneka dan atribut bando, selendang, sayur, dan peralatan masak dan makan.

Pada dasarnya bias gender muncul karna konstruk sosial yang sudah terlanjur tersebar di masyarakat. Sebenarnya, hal ini bukanlah hal yang fatal, karena tidak menyalahi kodrat masingmasing. Segala hal yang masih bisa diertukarkan, hendaknya menjadi bahan pertimbangan pendidik, agar stigma tertentu tidak bias gender. Contoh, olahraga, hobi, permainan, atribut, gambar untuk media ajar, bisa dipertukarkan dengan tetap mempertimbangkan batas kodrati.

Seperti main boneka besama anak lelaki, bermain bola bersama perempuan, lelaki yang membantu meringankan pekerjaan domestik dan perempuan yang juga mencari nafkah bukanlah dikotomi yang memperparah jurang antara lelaki dan perempuan. Sebab pada beberpa titik, meski diberi ruang, masih banyak perempuan yang menurut kaum feminis cenderung tertindas namun tidak menyadarinya. Justru feminism lah yang terlalu berlebihan menyamakan hal dengan cara mengidentikkan segalanya, sehingga bukannya menjadi solusi, jusru memperparah keadaan. 


\section{Mendidik Diri Agar Terhindar Dari Ekstrimisme}

Perempuan sebagai tiang negara adalah juga madrasah pertama bagi anaknya, pelipur lara sang suami, dan penggerak di wilayah sosialnya. Peran sebgai seorang ibu sangat penting bagi terbentuknya peradaban kecil dari lingkup rumah. Seorang penulis, Jarred Diamond yang pernah mendapat penghargaan Pulitzer mengatakan bahwa hancurnya tatanan peradaban suatu bangsa itu disebabkan 3 hal, yakni:

a. Hancurnya tatanan keluarga, mengikisnya peran ibu-ibu agar lebih sibuk dengan dunia luar, dan menyosialisasikan tentang dalih hak azasi dan emansipasi.

b. Hancurnya pendidikan, mengabaikan peran guru dan orang tua dalam mendidik anak. Guru disibukkan dengan peran administratif, silabus, hingga mengabaikan fungsinya sebagai pendidik (moral) yang bukan hanya mengajar. Dengan begitu, murid akan meremehkannya dan terlena dengan kehidupan liar. Sementara orang tua juga sibuk dengan persaingan karir, sehingga si anak kurang diperhatikan.

c. Hancurnya keteladanan dengan cara melibatkan rohaniawan atau tokoh agama ke rana politik praktis yang berorientasi pada jabatan dan materi semata.

Penyebab terjadinya kehancuran atau terkikisnya peradaban adalah kaena adanya ekstrimisme tanpa dasar yang jelas. Model ekstrimisme yang marak di tengah perkembangan masyarakat kekinian, terbagi menjadi dua macam, yakni ekstrimisme liberal dan ekstrimisme yang bercorak radikalisme .

Pertama adalah ekstrimisme liberal, yang juga bercirikan sekuleris, atheistik, maupun materialistik. Pola hidup mereka sangat dipengaruhi oleh cara pandang empiris dan positivistik. Materi dan gelamor dunia menjadi tujuan hidup. Mati menjadi hal yang sangat ditakuti atau bisa juga menjadi pelarian dari sakit hati. Budaya pop menghiasi lifestyle nya. Merasa malu jika dianggap ketinggalan jaman atau dianggap tidak modis.

Dalam teori semiotika yang disampaikan oleh Baudrillard, dimana semiotika adalah disiplin yang mempelajari segala sesuatuyang dapat digunakan untuk berdusta. Tanda-tanda realitas didekonstruksi sebagai komoditi daam wacana kapitalistik. Perempuan pun tak luput menjadi penarik minat konsumen. Syarat komoditi itu adalah pengemasan, pesona, kejutan, 


\section{An-Nisa', Volume XI Nomor 2 Desember 2018}

provokkasi, serta daya tarik (eye catching). Penampilan seksi dan mempesona dibutuhkan di pasaran karena apa yang nampak itulah yang dijual, meskipun keaslian produk kurang bermutu.

Perkembangan feminisme cukup pesat dalam memperjuangkan kebijakan untuk praktek advokasi (pembelaan) terhadap politik, ekonomi, dan kesetaraan sosial bagi perempuan. Pergerakan ini diilhami oleh pemikiran Mary Wollstenocraft dalam bukunya The vindication Rights of Woman tahun 1975 yang menuding bahwa pembodohan terhadap perempuan disebabkan oleh tradisi dan kebiasaan masyarakat yang membuat perempuan menjadi subordinasi laki-laki. Pergerakan perempuan yang dimotori oleh sekelompok perempuan di dunia Barat ini kemudian disambut secara global.. ${ }^{7}$ Menurut Gadis Arivia, ada tiga gelombang perkembangan feminisme, antara lain:

a. Pergerakan perempuan yang menyibukkan diri dengan berbagai aktivitas pergerakan perempuan, seperti menuntut hak dan keadilan. Ini diawali oleh pemikir-pemikir perempuan, yang dapat dibilang berada dibalik lahirnya The Convention of the Elimination of all Form of Discrimination Against Women (CEDAW) yang menginginkan adanya rumusan hak asasi perempuan yang dimulai pada tahun 1981 selanjutnya 180 negara meratifikasiya secara resmi untuk menyelaraskan hukum negaranya dengan CEDAW ${ }^{8}$.

b. Pergerakan perempuan masuk ke ruang akademis. Pada gelombang ini, lahir berbagai kajian perempuan dengan teori-teori mengenai keadilan gender, penyebab ketidakadilan dan cara mengatasinya. Pada gelombang dua ini teori feminisme banyak dipengaruhi oleh filsafat eksistensialisme yang dikembangkan oleh Jean Paul Satre dan teori feminisme dari Simone de Beauvoir serta teori-teori psikoanalisa.

\footnotetext{
7 Dr. Mardety Mardinsyah, M.Si. Aliran-aliran Pemikiran Feminisme. http://www.hermeneutikafeminisme.com/2016/01/24/aliran-aliran-pemikiran-fminisme-barat/. 2016. Diakses pada 28 Oktober 2018.

${ }^{8}$ Dr. Qurratul Ainiyah, M.HI. Keadilan Gender dalam Islam: Konvensi PBB dalam prespektif Mazhab Syafi'i. (Malang: Kelompok Intrans Publishing, 2015), h. 2
} 
c. Teori feminisme yang bersinggungan dengan pemikiran kontemporer dan berkutat pada masalah alienasi perempuan secara seksual, psikologis dan sastra dengan bertumpu pada bahasa sebagai sebuah sistem.

Beraneka macam teori feminism yang cenderung atheis seperti feminism radikal, sosial, liberal, maupun marxis ini dkenal sebagai feminism klasik. Namun corak pemikirannya masih berpengaruh hingga kini. Di sisi lain muncul beberapa feminism bercorak postmo yakni feminism postkolonial dimana menjadikan negara dunia ketiga sebagai bahan eksploitasi segala produk yang telah digunakan oleh dunia satu dan dua. Adapula feminism ekofeminisme yang mengaitkan antara perempuan dan alam semesta.

Ciri kelompok ekstrimisme yang kedua adalah ekstrimisme dengan membawa agama sebagai isu radikalisme. Feminisme agama memasuki area ini. Mereka beranggapan bahwa agama merupakan salah satu aktor utama dalam marginalisasi perempuan. Beberapa nilai agama ada yang melarang perempuan menjadi pemimpin larangan beribadah ketika dalam masa menstruasi, dan masih banyak contoh lain yang menjadi keprihatinan tersendiri bagi para feminis. Menurut mereka, doktin agama yang mengekang kebebasan itu terdapat di berbagai institusi agama seperti sekolah berbasis agama tertentu maupun kurangnya kiai, pastor, pendeta, bhiksu hingga wasi dari kalangan perempuan.

Kesalahpahaman yang mengidikasikan bahwa agama adalah bentuk marginalisasi sebenarnya disebabkan kurangnya engetahuan atau tidak mau tahu. Menstruasi bukanlah kutukan, melainkan salah satu proses kodrati biologis perempuan yang dari rahimnya itulah nanti, Tuhan menitipkan anak. Persoalan warisan adalah bentuk keadilan karena ketika oerempuan menikah, maka dia mendapatkan bagian dari suaminya juga. Sementara poligami adalah solusi kasuistik yang dijadikan momok. Padahal daripada selingkuh, maka sebaiknya menikah. Persoalan suami bisa adil atau tidak adalah tanggung jawab yang akan dihadapkan pada Ilahi Rabbi.

Pada Dialog Keummatan dengan tema pemahaman agama yang moderat penangkal radikalisme, Dr. Arifuddin Harishah menjelaskan bahwa radikalisme muncul dikarenakan kecewa pada ideologi sosial dan politik, kebuntuan dalam temukan solusi dalam persoalan penyimpangan-penyimpangan agama (maksiat), pemaknaan jihad secara rigid dan sempit, dan 


\section{An-Nisa', Volume XI Nomor 2 Desember 2018}

logika terbalik pada pemahaman hadits nahi mungkar, sombong dan kurang pengetahuan, memakasakan kebenaran, sikap ghuluw/ isyraf (berlebihan), dan tidak mau tahu.

Adapun deradikalisasi atau transfrormasi yang perlu dilakukan dalam menangkal radikalisme adalah sebagai berikut:

1. Mengubah sikap egoisme terhadap kebenaran sebagai milik seseorang atau sekelompok tertentu saja perlu diubah menjadi lebih terbuka (pluralis)

2. Konsep identitas yang serba simbolistik diubah menjadi konsep yang dipahami secara substansial dan bernilai universal.

3. Pemahaman yang cenderung pada textual corpus tertutup di transformasi menjadi pemahaman yang lebih contextual corpus terbuka.

Feminisme memiliki isu yang cukup bagus untuk diperjuangkan,, namun sayangnya penanganan masalah justru memperparah kondisi diakibatkan salah kaprah. Ibaratnya, jika seorang dokter salah mendiagnosa penyakit, maka jadinya penyakit tambah para. Maksud gerakan adalah mengangkat derajat perempuan justru lebih memperburuk kondisi perempuan dengan cara yang berbeda. Ekofeminiisme tidak lagi membahas relasi antara lelaki dan perempua. Kekerasan yang terjadi pada budaya tertentu dianggap keberagaman yang harus dihargai, Sementara kekurangan feminisme agama adalah cenderung pada penafsiran kitab saja.

Pada dasarnya perbedaan antara lelaki dan perempuan merupakan masalah simetri atau keseimbangan, bukan masalah yang satu lebih sempurna (lelaki) dibandingkan yang lain (perempuan) ${ }^{9}$. Feminisme tertentu yang menganggap lelaki sebagai saingan pun banyak yang memilih hidup sendiri atau dengan sesame jenis. Tantunya hal ini lah yang merusak tatanan dan moril masyarakat pada umumnya. Penyatuan antara lelaki dan perempuan bukan hanya sekedar nafsu belaka, tapi itulah mahakarya terindah dari Tuhan agar keberlangsungan kehidupan tetap berjalan dengan indah dan damai.

Kesetaraan atau persamaan itu bersandar pada keadilan proporsional, bukan keidentikan yang harus disamakan dan beerakhir dengan kezaliman. Kesetraan bisa juga dimaknai dengan memahami adanya perbedaan di beberapa hal tanpa menimbulkan penindasan. Dan muncullah gerakan anti-tesis yang menyeru kaum wanita agar kembali ke pangkal jalan, sebut saja

\footnotetext{
${ }^{9}$ Murtadha Muthahhari. Filsafat Perempuan dalam Islam. (Yogyakarta: RausyanFikr Institute, 2012), h. 135
} 
umpamanya Erin Patria Pizzey (penulis buku Prone To Viloence), Iris Krasnov (penulis buku Surrendering to motherhood). Mereka bisa dikatakan yang mewakili arus balik penentang feminisme.

Menurut mereka, gerakan feminis hanya akan menyengsarakan kaum wanita. karena perbedaan gender tidak harus dipahami sebagai perseteruan dan pertarungan antar kelompok atau saling berebut posisi baik dari segi keseharian, politik, sosial, dan ekonomi. Melainkan dalam membangun kerjasama dan hubungan timbal balik, dalam arti saling menopang bahu membahu membangun sebuah keluarga, bangsa dan negara, saling melengkapi, saling mengisi dan saling menghargai satu sama lain.

Selama masih berada dalam koridor ajaran agama, kemanusiaan, keadilan, etika, dan kebenaran, maka konsepdalam memperjuangkan kedudukan \& hak perempuan harus terus dipertahankan. Jadi sangat ironis, ketika dunia Barat sudah mulai meninggalkan feminism, justru di beberapa tempat feminisme masih di elu-elukan. Hak azasi manusia, tanpa di undangundangkan pun harus dilaksanakan karena itu adalah dasar menghormati sesame manusia. Ketika ketimpangan terjadi, maka kita membela atas nama kemanusiaan, bukan tambah memperjelas dikotomi atau subordinasi salah satu jenis kelamin.

\section{Menggali Potensi Diri}

Dalam menghadapi tantangan zaman yang serba digital ini, maka kaum perempuan khususnya muslimah sebagai garda pembentukann peradaban negeri, maka perlu menggali potensi diri untuk menjadi manusia seutuhnya.Diantaranya yakni dengan mengetahui tujuan penciptaan, membangun pandangan dunia, mengenali potensi diri, dan menjadi pribadi produktif dalam lingkup domestik maupun rana sosial.

Mengetahui tujuan penciptaan yakni memahami fungsi penciptaan manusia terutama sebagai perempuan. Kita diciptakakn untuk beribadah sebagaimaa Q.S Adz-Dzariyat: 56). Dan kita semua akan diminta pertanggung jawabannya di akhirat kelak seperti yang termaktub dalam (Q.S. Al-Qiyamah;36).

Selanjutnya adalah penting membentuk pandangan dunia sebagai alat untuk menganaliasa realitas. Pandangan dunia materialistik akan membuat perempuan menjadikan 


\section{An-Nisa', Volume XI Nomor 2 Desember 2018}

pejalanan hidup ini semata untuk mengejar materi, menguasai suami, dan menjadi budak materi. Jadi ketika melakukan segala sesuatu ideologi tauhid menjadi landasan geraknya. Kemanapun dia menghadap dan berbuat, maka yang di dapati hanyalah Allah semata. Sebagaimana tertera pada Q.S. Al-Baqarah:115)

Setelah mengetahu konsep penciptaan dan membentuk prespektif tauhid dalam membingkai realitas, maka perlu megenali potensi diri. Bahwasanya setiap manusia pasti dibekali ketermpilan. Keterampilan yang pro gender dan memasuki pelbagai kursus menjahit, buka rumah makan, dsb. Produktivitas itu bisa berupa berkarir maupun membuka lapangan kerja sendiri di rumah seperti buat untuk alat campuran, bisnis barang atau kue. Begitupun yang hendak menjadi ibu rumah tangga, maka musti menjadi sosok ibu yang porfesional.

Pergolakan bangsa masih terus berlangsung, tetap jangan mudah terpengaruh hanya dengan asumsi atau penilaian inderawi semata. Perlu bersikap bijak, dewasa, dan meggunakan akal dalam memikirkan segala realitas yang terjadi, mempertimbangkan dengan akal sehat sehingga tidak terjebak pada pusaran hoax, hatespeech, narkoba, radikalisme, hingga terorisme.

\section{Kesimpulan}

Teori feminisme yang seyogianya membangun atau membela hak azasi manusia khususnya kaum perempuan, justru menjadi bentuk penindasan baru jika tidak dipahami dan didiagnosa dengan baik. Padahal adanya perbedaan tidak meniscayakan ketidaksempurnaan bagi perempuan. Kesetaraan pun bermakna keadilan yang juga tidak harus sama dengan mempertimbangkan kodrati seperti fisik, psikologi, dan perasaan.

Dalam menghadapi tantangan zaman oleh kaum ekstrimisme, maka perempuan harus dibekali dengan mengetahui tujuan penciptaan, membangun pandangan dunia, mengenali potensi diri, dan menjadi pribadi produktif dalam lingkup domestik maupun rana sosial. Ketika ketimpangan di masyarakat terjadi, maka kita membela atas nama kemanusiaan, bukan tambah memperjelas dikotomi atau subordinasi salah satu jenis kelamin.

\section{Daftar Pustaka}

Ainiyah, Dr. Qurratul Keadilan Gender dalam Islam: Konvensi PBB dalam prespektif Mazhab Syafi'I, Malang: Kelompok Intrans Publishing, 2015. 
Fakih, Mansour, Analisis Gender dan Transformasi Sosial, Yogyakarta: Pustaka Pelajar. 2013.

Hamalik, Oemar. Dasar-Dasar Pengembangan Kurikulum. Bandung: PT. Remaja Rosdakarya, 2006.

Hidayat, Rahmat. Pengantar Sosiologi Kurikulum, Jakarta: RajawaliP ress, 2011.

Mardinsyah, Dr. Mardety, Aliran-aliran Pemikiran Feminisme. http://www.hermeneutikafeminisme.com/2016/01/24/aliran-aliran-pemikiran-fminismebarat/. 2016. Diakses pada 28 Oktober 2018.

Miller J.P. \& Seller, W. Curriculum, Perspectives, and Practices. New York aand London: Longman, 1985.

Muthahhari, Murtadha, Filsafat Perempuan dalam Islam. Yogyakarta: RausyanFikr Institute, 2012.

Piliang, Yasraf Amir. Hipersemiotika: Tafsir Cultural Studies Atas Matinya Makna, Bandung: Jalasutra, 2003.

Zulmi, Billah Nurlaili dan Lisytani, Refti Handini, Bias Gender dalam Buku Tematik Siswa Kurikulum 2013: (Studi Semiotika Ketidaksetaraan Gender dalam Pendidikan) . (Jurnal Paradigma Vol. 05 No.3 Tahun 2017). 